\title{
Investigation of VLF and HF waves showing seismo-ionospheric anomalies induced by the 29 September 2009 Samoa earthquake
} $\left(M_{\mathrm{w}}=\mathbf{8 . 1}\right)$

\author{
M. Akhoondzadeh ${ }^{1,2}$, M. Parrot ${ }^{2}$, and M. R. Saradjian ${ }^{1}$ \\ ${ }^{1}$ Remote Sensing Division, Surveying and Geomatics Engineering Department, University College of Engineering, \\ University of Tehran, Tehran, Iran \\ ${ }^{2}$ Laboratoire de Physique et Chimie de l'Environnement et de l'Espace (LPC2E)/CNRS, UMR6115, Orléans, France
}

Received: 27 December 2009 - Revised: 30 April 2010 - Accepted: 10 May 2010 - Published: 28 May 2010

\begin{abstract}
In Samoa Islands, a powerful earthquake took place at 17:48:10.99 UTC (06:48:10.99 LT) on 29 September 2009 with a magnitude $M_{\mathrm{w}}=8.1$. Using ICE (Instrument Champ Electrique) and IMSC (Instrument Magnetic Search Coil) experiments onboard the DEMETER (Detection of Electromagnetic Emissions Transmitted from Earthquake Regions) satellite we have surveyed possible variations in electromagnetic signals transmitted by the groundbased VLF transmitter NPM in Hawaii and in HF plasma waves close to the Samoa earthquake during the seismic activity. The indices $D_{\mathrm{st}}$ and $K_{\mathrm{p}}$ were used to distinguish preearthquake anomalies from the other anomalies related to the geomagnetic activities. In a previous study we have shown that anomalies in IAP (plasma analyzer) and ISL (Langmuir probe) experiments onboard the DEMETER and also TEC (Total Electron Content) data appear 1 to 5 days before the Samoa earthquake. In this paper we show that the anomalies in the VLF transmitter signal and in the HF range appear with the same time scale. The lack of significant geomagnetic activities indicates that these anomalous behaviors could be regarded as seismo-ionospheric precursors. It is also shown that comparative analysis is more effective in seismoionospheric studies.
\end{abstract}

\section{Introduction}

The preseismic perturbations in lithosphere, atmosphere and ionosphere without significant solar and geomagnetic disturbances are considered as hint of impending earthquakes

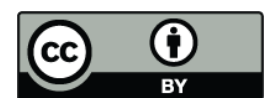

Correspondence to: $\mathrm{M}$. Akhoondzadeh (makhonz@ut.ac.ir) (earthquake precursors). The ionospheric anomalies usually happen in the D-layer, E-layer and F-layer, and may be observed 1 to 10 days prior to the earthquake and continues a few days after it (Parrot, 1995; Liu et al., 2004; Hayakawa and Molchanov, 2002; Pulinets and Boyarchuk, 2004; Hobara and Parrot, 2005).

Daily variations of the ionosphere depend on season, geographic location, thermospheric winds, traveling ionospheric disturbances, severe weather in the atmosphere, tsunami and other unknown parameters. Moreover, the ionospheric parameters are affected by solar geophysical conditions and geomagnetic storms especially in the equatorial and polar regions. Auroral activity has also an important role in the mid-latitude ionosphere perturbations. Therefore, the measured plasma parameters may display variations in absence of seismic activity. Consequently, to discriminate the seismo-ionospheric perturbations from the geomagnetic disturbances, the geomagnetic indices $D_{\text {st }}$ and $K_{\mathrm{p}}$ (http://spider. ngdc.noaa.gov) have been checked. The $K_{\mathrm{p}}$ index monitors the planetary activity on a worldwide scale whereas the $D_{\text {st }}$ index records the equatorial ring current variations (Mayaud, 1980).

There exist hypothesis to explain the seismic electromagnetic mechanism based on geophysical and geochemical processes:

- direct wave production in a wide band spectrum by compression of rocks close to earthquake epicenter could be likely related to piezo-electric and triboelectric effects;

- rising fluids under the ground would lead to the emanation of warm gases and then excitation of atmospheric gravity waves;

Published by Copernicus Publications on behalf of the European Geosciences Union. 
- activation of positive holes that can reach the ground surface;

- emissions of radioactive gas or metallic ions such as radon which increase the Earth surface potential.

Pre-seismic electric field and its polarity cause the electrons in the F-layer to penetrate to lower layers and therefore to create anomaly in the ionospheric parameters. The thin layer of particles created before earthquakes due to ion radiation from the Earth has a main role in transferring electric field to above atmosphere and then to the ionosphere. The penetration of this electric field to the ionosphere was first analytically calculated in Park and Dejnakarintra (1973) and then applied to the seismo-electromagnetic process by Kim et al. (1994) and Pulinets et al. (2000). The vertical electric field on the ground surface is transformed into an electric field perpendicular to the geomagnetic field lines. This zonal component leads to plasma density anomalies, which are observed in the earthquake area (Parrot, 1995; Hayakawa and Molchanov, 2002; Pulinets et al., 2003; Molchanov and Hayakawa, 2008; Namgaladze et al., 2009). In vicinity of the equatorial anomaly, a zonal component can be generated using the mechanism proposed by Pulinets (2009).

Many papers and special monographs have been published on satellite observations of the ionospheric plasma, the flux of charged particles, the DC electric field, electromagnetic waves and geomagnetic field associated with seismic activity (Hayakawa and Molchanov, 2002; Pulinets and Boyarchuk, 2004).

In order to discriminate these effects, it is necessary to carry out regular satellite observations in the ionosphere with highly sensitive measurements over both seismically active and quiet regions. This leads to create an appropriate database for statistical study of the seismo-ionospheric effects. The French micro-satellite DEMETER (Detection of Electromagnetic Emissions Transmitted from Earthquake Regions) was launched on 29 June 2004 with this purpose. The main scientific objective of DEMETER is to detect anomalous variations of electromagnetic waves, particle fluxes and thermal plasma parameters which could be related to seismic activity. The orbit of DEMETER is polar, sunsynchronous, and circular with a low altitude $(\sim 660 \mathrm{~km}$ at the time of the event). The satellite provides a nearly continuous survey of the plasma, waves and energetic particles by different experiments at 10:30 and 22:30 Local Time (LT). There are two modes of operation: (i) a survey mode to record low bit rate data all around the Earth at invariant latitudes less than $\sim 65^{\circ}$, and (ii) a burst mode to record high bit rate data above seismic regions. Parrot et al. (2006b), Sarkar et al. (2007) and Akhoondzadeh et al. (2010) described examples of variation of plasma parameters recorded by DEMETER data over epicenters of some earthquakes before their occurrence. Moreover, pre seismic anomalies in the registered VLF transmitter signals by electromagnetic experiments of DEMETER have been already reported
(Molchanov et al., 2006; Rozhnoi et al., 2007, 2008; Slominska et al., 2009). The VLF transmitter signals normally propagate in the Earth-ionosphere wave guide. But it can escape from the ionosphere mainly during night time in case of ionospheric irregularities. This could occur above the seismic area during the earthquake preparation processes.

Recently we have observed seismo-ionospheric anomalies using DEMETER experiments and TEC (Total Electron Content) data during a recent (29 September 2009) major earthquake $\left(M_{\mathrm{w}}=8.1\right)$ close to the Samoa Islands (Akhoondzadeh et al., 2010). In Sect. 2 we will study on one hand the signal of a VLF transmitter signal recorded by DEMETER at the time of the same earthquake, and on the other hand the HF data recorded by the satellite. Section 3 will present discussion and conclusions.

\section{Data analysis and results}

In order to clear up uncertainties for earthquake anomaly detection, this study is based on a few types of precursors and experiments. We have analyzed the variations of electromagnetic spectrograms retrieved by ICE (Instrument Champ Electrique) and IMSC (Instrument Magnetic Search Coil) experiments data concerning the closest DEMETER satellite approaches to the Samoa earthquake epicenter from $1 \mathrm{Au}-$ gust to 5 October 2009. The characteristics of Samoa earthquake accompanied with its aftershocks information can be found in Table 1 and a map is shown in Fig. 1. Optimum distance between the satellite and the earthquake epicenter was selected in terms of DEMETER satellite altitude and earthquake zone radius. The radius of seismic area can be estimated using the Dobrovolsky formula $R=10^{0.43 M}$ where $R$ is the radius of the earthquake preparation zone, and $M$ is the earthquake magnitude (Dobrovolsky et al., 1979). To take into account this distance, data have been selected when orbits are at $\pm 10^{\circ}$ in longitude and at $\pm 2^{\circ}$ in latitude from the epicenter.

\subsection{Observed anomalies using ICE and IMSC experiments onboard DEMETER satellite}

The ICE experiment uses four electric probes to measure power spectrum density of the electric field in a frequency range from DC up to $3.5 \mathrm{MHz}$ (Berthelier et al., 2006). Measurements of the three magnetic components of the magnetic field are performed by the IMSC experiment (Parrot et al., 2006a). During operation of DEMETER satellite in the survey mode, the power spectra of one electric and one magnetic component are provided with frequency and time resolutions of $19.53 \mathrm{~Hz}$ and $2.048 \mathrm{~s}$, respectively in the VLF range between $20 \mathrm{~Hz}$ and $20 \mathrm{kHz}$. In the $\mathrm{HF}$ range from $3.2550 \mathrm{kHz}$ to $\sim 3.25 \mathrm{MHz}$, the frequency resolution of the power spectrum is $3.2550 \mathrm{kHz}$. 
Table 1. Characteristics of the Samoa earthquake and its main aftershocks (reported by http://earthquake.usgs.gov/).

\begin{tabular}{llclc}
\hline Date & Time & $\begin{array}{c}\text { Geographic } \\
\text { latitude, longitude }\end{array}$ & $\begin{array}{l}\text { Magni- } \\
\text { tude } \\
\left(M_{\mathrm{W}}\right)\end{array}$ & $\begin{array}{l}\text { Focal } \\
\text { depth } \\
(\mathrm{km})\end{array}$ \\
\hline 29 Sept 2009 & $17: 48: 10.99$ & $15.49 \mathrm{~S}, 172.10 \mathrm{~W}$ & 8.1 & 18.0 \\
29 Sept 2009 & $17: 56: 05.79$ & $15.35 \mathrm{~S}, 173.16 \mathrm{~W}$ & 6.0 & 10.0 \\
29 Sept 2009 & $23: 45: 03: 46$ & $15.83 \mathrm{~S}, 172.55 \mathrm{~W}$ & 6.0 & 10.0 \\
2 Oct 2009 & $01: 07: 39: 26$ & $16.33 \mathrm{~S}, 173.47 \mathrm{~W}$ & 6.1 & 8.0 \\
\hline
\end{tabular}

With the data collected by ICE experiment it is possible to survey abnormal variations in recorded VLF transmitter signals during seismic activity when the signal path between the transmitter and the satellite is going above the active seismic area. The VLF signals are extremely affected by sudden ionospheric disturbances at day time (Molchanov et al., 2006). Therefore only the night data have been analyzed. Figure 2a represents the time series of 1550 computed spectra of an electric component (E12 which is perpendicular to the satellite velocity) in the VLF range registered close to the epicenter during different days. To produce the spectrogram shown in Fig. 2a, all these spectra have been plotted close to each other even if there is a big time interval when there is a jump to another day. Due to the orbitography and to the incompleteness of the satellite data several gaps are observed during the studied time interval. The vertical lines in the spectrogram are related to sferics. Figure $2 \mathrm{a}$ also shows horizontal sporadic transmissions in a frequency range around $18.6 \mathrm{kHz}$ which are powerful and stable signals in comparison with the other ones observed on the spectrogram. These signals are related to the powerful NPM ground-based transmitter in Lualualei, Hawaii which is operating at $21.4 \mathrm{kHz}$. NPM is located in the northern hemisphere $\left(21^{\circ} 25^{\prime} \mathrm{N}, 158^{\circ} 09^{\prime} \mathrm{W}\right)$, but its magnetically conjugate point is not far from the Samoa earthquake (see Fig. 1). The NPM signal is so strong that it is not enough attenuated by the antialiasing filter of the experiment and that its frequency appears at $18.6 \mathrm{kHz}$ (the Nyquist frequency $20.0 \mathrm{kHz}$ minus $1.4 \mathrm{kHz}$ ) in the VLF spectra. Owing to the propagation conditions of the transmitter signal through the ionosphere, broadening of the spectrum around the transmitter frequency is observed (Fig. 2a). In order to enhance the unusual variations of the recorded VLF transmitter signal, the median $\left(M_{i}\right)$ and the inter-quartile $\left(\mathrm{IQR}_{i}\right)$ parameters are utilized to construct the higher and lower bounds $\left(x_{\text {high }, i}\right.$ and $\left.x_{\text {low }, i}\right)$ for each frequency channel of the onboard computed spectrograms according to the following equations:

$$
\begin{aligned}
& M_{i}=\operatorname{Median}(I(i, j))_{i=1}^{N} \quad N=1024 \\
& x_{\text {high }, i}=M_{i}+\mathrm{IQR}_{i} \\
& x_{\text {low }, i}=M_{i}-\mathrm{IQR}_{i}
\end{aligned}
$$

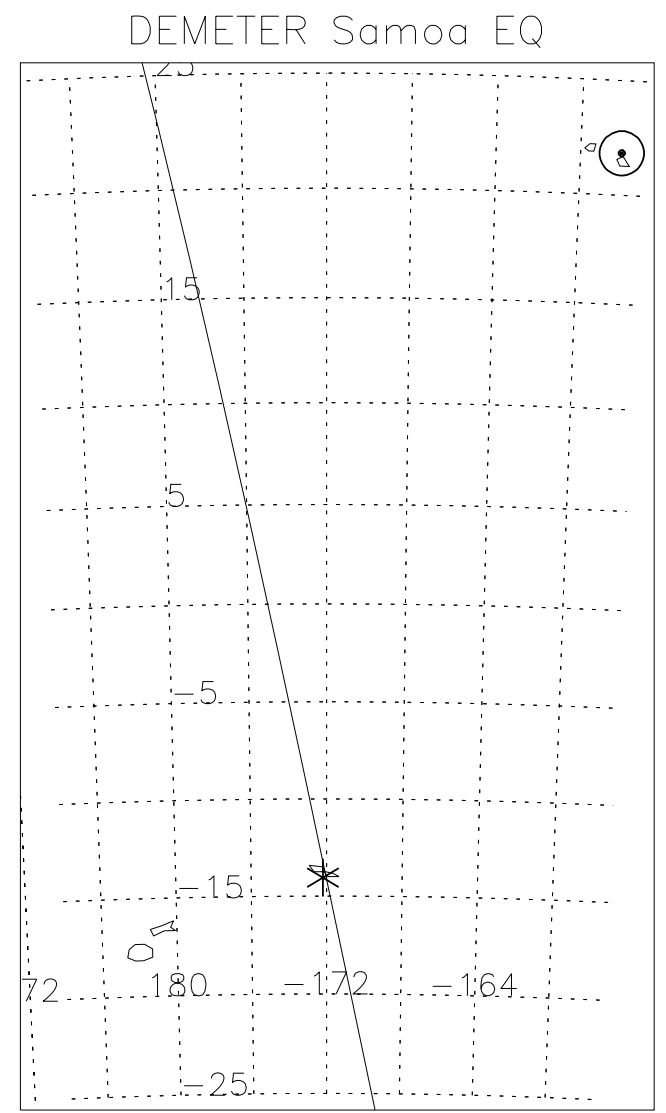

Fig. 1. Locations of the earthquake epicenter $(*)$, of the VLF transmitter NPM (circle around a dot) and of one DEMETER orbit on 25 September 2009 (4 days before the event).

$$
\begin{aligned}
& x_{\text {low }, i}<I(i, j)<x_{\text {high }, i} \Rightarrow-1<\frac{I(i, j)-M_{i}}{\mathrm{IQR}_{i}}<1 \\
& D x=\frac{I(i, j)-M_{i}}{\mathrm{IQR}_{i}}
\end{aligned}
$$

where $i, j, N$ and $I(i, j)$ are the index of the frequency components (between 1 and 1024), the index for all analyzed spectra, the total number of frequency components (1024), and the recorded intensity of the $j$ spectrum at the $i$ th frequency component, respectively. Therefore, if the absolute value of the $D x$ would be greater than one, $(|D x|>1)$, the behavior of the relevant parameter is regarded as anomalous. According to Eq. (4), $p= \pm 100 \cdot(|D x|-1) / 1$ indicates the percentage of parameter change from the undisturbed state. Using the mentioned equations the disturbed state, variations exceed the allowable bounds $(M \pm \mathrm{IQR})$, was defined for each frequency channel during all recorded spectrograms (Figs. 2b, 3b, and 4b). By visual inspection of Fig. 2a unusual behaviors of the transmitter signal can be noticed at three different parts. These parts which are seen with red arrows on the VLF spectrogram have been also detected by 

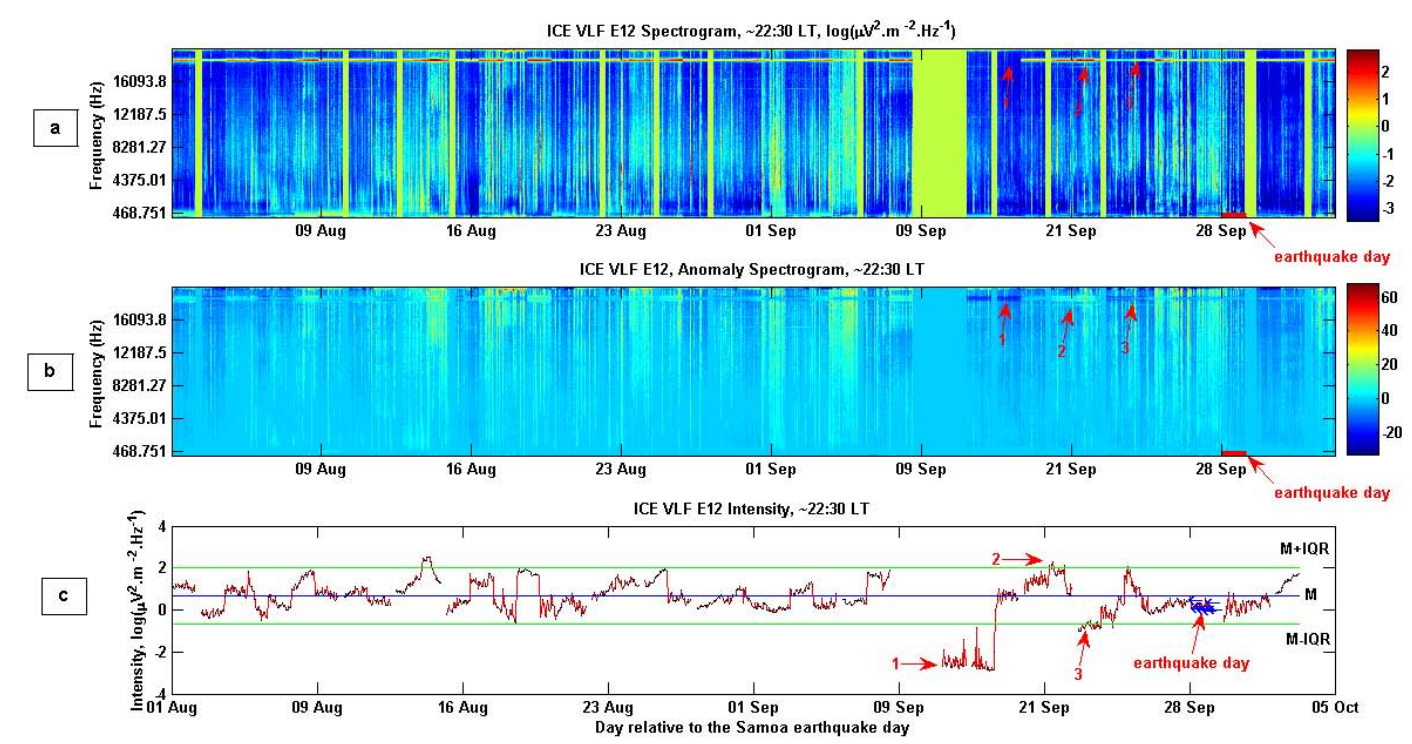

Fig. 2. Results of the DEMETER data analysis concerning the Samoa earthquake (29 September 2009) from 1 August to 5 October 2009 at $\sim 22: 30$ LT. Due to the operation of satellite in safe mode a time gap is observed from 7 to 15 September 2009. The earthquake day is represented by a red tick below the X-axis. (a) ICE VLF spectrogram of the E12 electric component. The intensity of the spectrogram is color-coded according to the scale on the right. (b) Detected anomaly in the ICE VLF spectrogram of the E12 electric component. The anomaly is color-coded according to the scale on the right. (c) Intensity of ICE VLF spectrogram of the E12 electric component around the virtual NPM transmitter frequency (see text for explanation). For this panel the green horizontal lines indicate the higher and lower bounds $(M \pm \mathrm{IQR})$. The blue horizontal line indicates the median value $(M)$. In all panels, the $\mathrm{X}$-axis represents days relative to the occurrence of the Samoa earthquake.

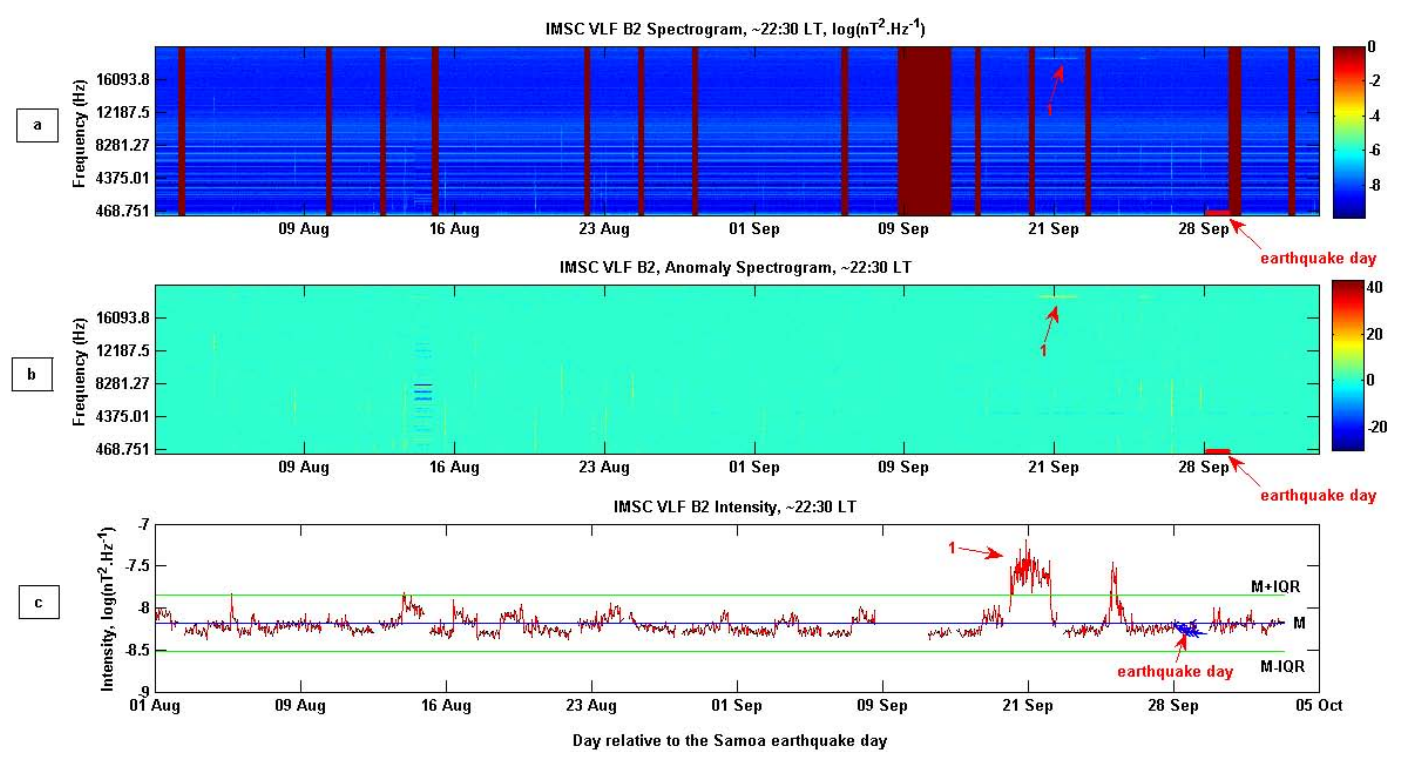

Fig. 3. Same as Fig. 2 but for IMSC VLF spectrogram of the B2 magnetic component.

the applied anomaly detection method (Fig. 2b). In order to do better analysis, for each spectrogram the median of the registered transmitter intensities in a frequency range around $18.6 \mathrm{kHz}$ have been calculated. Figure $2 \mathrm{c}$ represents the time series of the calculated median of the transmitter signal according to the spectrogram time scale. The green horizontal lines in the Fig. 2c correspond to the higher and the lower bounds, whereas the blue horizontal line is the median of the relative data. The fast variations of the VLF signals are due to ionospheric irregularities. Figure $2 \mathrm{c}$ also indicates that the median of the VLF electric spectrogram around the transmitter frequency exceed the defined bounds at the three above 

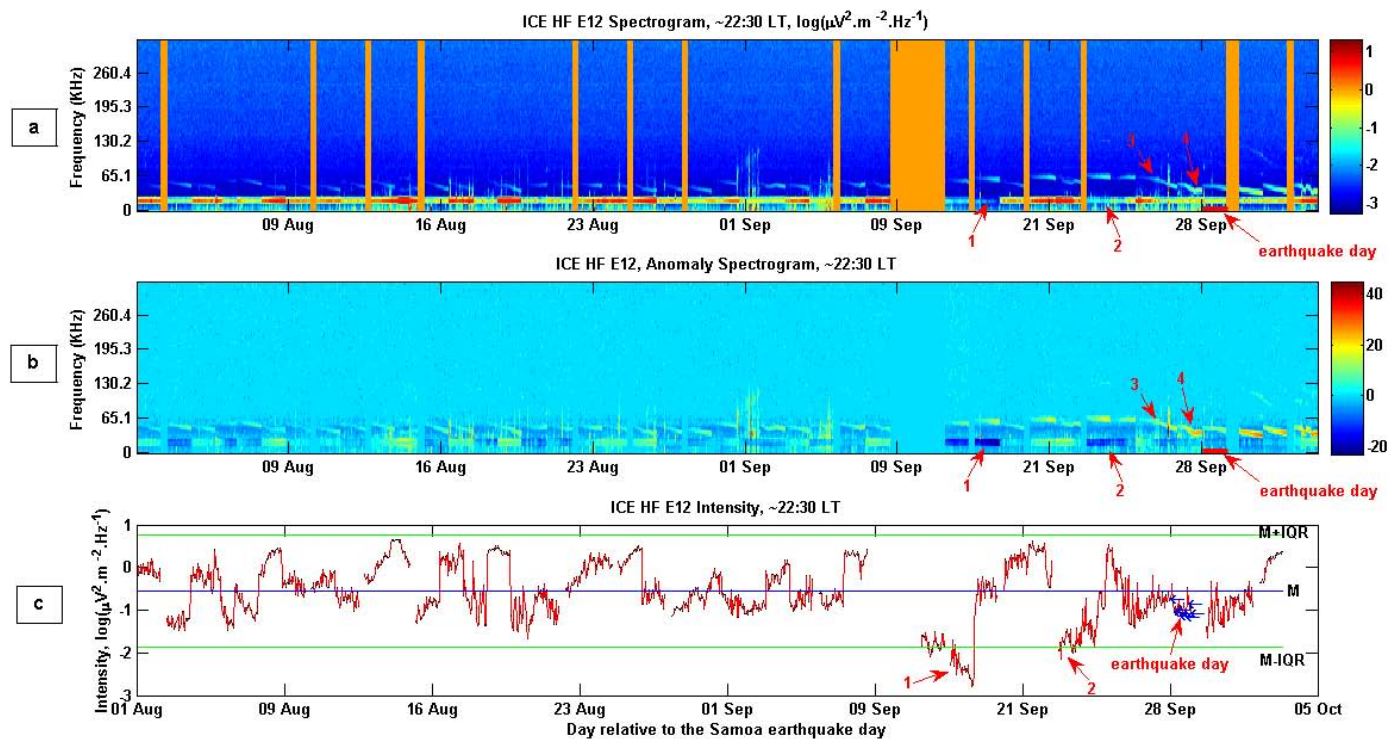

Fig. 4. Same as Fig. 2 but for ICE HF spectrogram of the E12 electric component.

mentioned parts (the red arrows 1, 2, and 3 in Fig. 2c). For the first time interval which is between 13 and 11 days before the earthquake, no transmitter signal is observed. It means that the transmitter was most probably switched off during the satellite observation (the first red arrow in Fig. 2a, b, and c and the first red arrow in Fig. 4a, b, and c). The second red arrow in Fig. 2a, b, and c represent the intense appearance of the transmitter waves in the VLF electric spectrogram 7 and 8 days before the earthquake. This sharp appearance is also seen in the VLF magnetic spectrogram at the same time (the first red arrow in Fig. 3a, b, and c). Figure 3a illustrates the time series of about 1550 spectrograms of a magnetic component (B2) in the VLF range from 1 August to 5 October 2009. The Panels $3 \mathrm{~b}$ and $\mathrm{c}$ have been achieved with the similar method which has been already devoted for the VLF electric spectrogram. This strong electromagnetic enhancement of the VLF transmitter wave is due to the broadening of the spectral component at the transmitter frequency. This broadening is enhanced when the VLF wave crosses ionospheric irregularities (Bell and Ngo, 1988, 1990).

The last part (the third red arrow in Fig. 2a, b, and c) corresponds to attenuation of the transmitter signals when it crosses the disturbed ionosphere 4 and 5 days before the earthquake. This fading of the signal can be associated to an increase of the ionospheric density because during the ionospheric propagation the signal attenuation is directly proportional to the plasma density (Cannon and Bradley, 2003). The geomagnetic conditions are quiet on these dates $(K \mathrm{p}<2.5$ and $D$ st $>-20(\mathrm{nT}))$. A dominant anomaly was observed in electron density parameter measured by ISL (Langmuir probe) sensor, 5 days before the earthquake at nighttime (Akhoondzadeh et al., 2010). Using the analysis of the DEMETER data, Molchanov et al. (2006) reported a drop of the VLF signals radiated by ground transmitters prior to large earthquakes. Based on their proposed model the penetration of atmospheric gravity waves (AGW), which are induced by the gas-water release from the earthquake preparatory zone into the ionosphere leads to modification of the natural ionospheric turbulence. Accordingly, significant drops of the VLF signal amplitude are deduced by the resonant scattering of the VLF waves caused by perturbations on the ionosphere plasma density. Their results also indicated that the size of the perturbed area increases with the magnitude of the earthquake.

\subsection{Observed anomalies using HF data of ICE experiment onboard DEMETER satellite}

The data presented in Fig. 4a, b, and c are related to the HF electric spectrogram, detected anomalies and variations of the detected transmitter signals in the HF range from $1 \mathrm{Au}-$ gust to 5 October 2009. The results of the ICE HF data (an electric component E12) seem to confirm the observations in the ICE VLF spectrogram. The arrows 1 and 2 in Fig. 4a, b, and c coincide with the arrows 1 and 3 in Fig. 2a, b, and c with the similar characteristics.

By visual inspection of HF electric spectrogram an interesting set of discrete harmonic emissions above transmitter frequency can be noticed (Fig. 4a). There exist hypothesis to explain the origin of these harmonic emissions; Electron and ion heating induced by the powerful transmitter VLF (Parrot et al., 2007); second order cyclotron resonance mechanism (Riggin and Kelley, 1982); lower hybrid parametric instabilities caused by VLF transmitters signals (Bell and Ngo, 1988, 1990) and HF heating of the lower ionosphere. Based on these mechanisms, source of the particles that produce 
quasi-periodic emissions propagating in the magnetosphere is not exactly known. But there is no doubt that ionospheric heating can excite these banded emissions.

The arrows 3 and 4 in Fig. $4 \mathrm{a}$ and $\mathrm{b}$ represent the unusual variations in these periodic radiations around the earthquake day. These emissions have regular behaviors before 18 September 2009 (11 days prior to the earthquake). But after this date emissions have a tendency to extend towards higher frequencies and reach to maximum frequency $(\sim 65 \mathrm{kHz})$, 2 days before the earthquake (the third red arrow in Fig. 4a and $b$ ).

The time series of the electron temperature variations, measured by the ISL experiment, display a sudden increase in electron temperature, 2 days before the earthquake, at $\sim 22: 30$ LT (Akhoondzadeh et al., 2010).

Intense emissions also appear 1 day before the earthquake and this state remains at the lower frequency until several days after the event. These unusual signatures of transmitter have been also detected by applied anomaly detection method (the fourth red arrow in Fig. 4a and b).

\section{Discussion and conclusions}

A dominant anomaly is observed in total ion density, electron density and ion temperature parameters measured by IAP (plasma analyzer) and ISL sensors at $\sim 10: 30 \mathrm{LT}, 4$ days before the earthquake. Unusual TEC variations 4 days before the earthquake confirm the results deduced by the DEMETER data (Akhoondzadeh et al., 2010).

In this paper, one of the promising results is that VLF transmitter signal and HF wave show anomalies with the same time scale as the ionospheric density. In all the measured parameters during night time 5 days prior to the earthquake these perturbations can be related to the magnitude of this powerful earthquake $\left(M_{\mathrm{w}}=8.1\right)$ and likewise, quiet geomagnetic activities around the earthquake date did not modify the detected anomalies. This is consistent with the fact that the efficiency of the anomalous electric field penetration into the ionosphere at night is higher than in daytime $(\mathrm{Pu}-$ linets and Boyarchuk, 2004). On the mentioned date, the ICE measurements reveal the largest attenuation of the NPM VLF transmitter signals at $\sim 22: 30$; ISL experiment reaches the maximum value of electron density (Akhoondzadeh et al., 2010); and TEC anomaly map retrieved using GPS data indicate that the intense abnormal TEC unusual variations last $8 \mathrm{~h}$ (Akhoondzadeh et al., 2010). This attenuation of the VLF signal can be attributed to an increase of the plasma density because during the ionospheric propagation the signal attenuation is directly proportional to the ionospheric density (Cannon and Bradley, 2003).

It should be noted that it is not expected that precursors can appear for any earthquake. Since not any individual precursor can be used as an accurate stand alone tool for the earthquake prediction, it is required to exploit and in- tegrate different kinds of precursors from different experiments. Therefore, in order to obtain significant results we used from DEMETER ICE and IMSC experiments to detect striking anomalies in electromagnetic field in the vicinity of the Samoa earthquake epicenter several days before its occurrence.

Our results indicate that the highest intensity of preearthquake anomaly appeared within the time interval 15 days before this strong earthquake. Because the geomagnetic activity was very quiet during the days around of the Samoa earthquake date, the detected anomalies can be interpreted as pre-seismic ionospheric variations. However, it is necessary to take into account that the ionosphere has complicated behavior even under quiet geomagnetic condition and that the measured parameters sometimes display variations in quiet seismic condition that can be associated to other unknown effects. The seismo ionospheric anomalies represented in this paper are promising for the short term prediction but attention has to be paid that further investigation is required to obtain a very accurate regional model of quiet time ionosphere to discriminate seismic precursors from the background of daily variations.

Acknowledgements. This work was supported by the University of Tehran (for MA) and Centre National d'Etudes Spatiales (for MP). The authors thank J. J. Berthelier the PI of ICE for the use of the data.

Edited by: M. E. Contadakis

Reviewed by: two anonymous referees

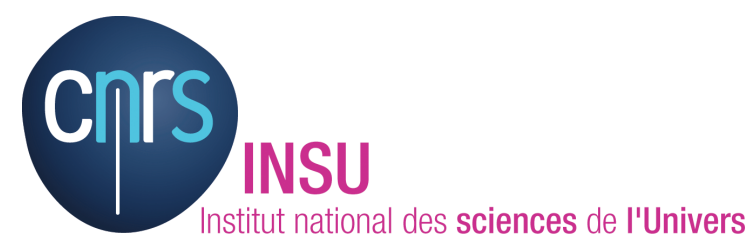

The publication of this article is financed by CNRS-INSU.

\section{References}

Akhoondzadeh, M., Parrot, M., and Saradjian, M. R.: Electron and ion density variations before strong earthquakes $(M>6.0)$ using DEMETER and GPS data, Nat. Hazards Earth Syst. Sci., 10, 718, doi:10.5194/nhess-10-7-2010, 2010.

Bell, T. F. and Ngo, H. D.: Electrostatic waves stimulated by coherent VLF signals propagating in and near the inner radiation belt, J. Geophys. Res., 93, 2599-2618, 1988.

Bell, T. F. and Ngo, H. D.: Electrostatic lower hybrid waves excited by electromagnetic whistler mode waves scattering from planar magneticfield-aligned plasma density irregularities, J. Geophys. Res., 95, 149-172, 1990. 
Berthelier, J. J., Godefroy, M., Leblanc, F., Malingre, M., Menvielle, M., Lagoutte, D., Brochot, J. Y, Colin, F., Elie, F., Legendre, C., Zamora, P, Benoist, D., Chapuis, Y., Artru, J., and Pfaff, R.: ICE, the electric field experiment on DEMETER, Planet. Space Sci., 54, 456-471, 2006.

Cannon, P. S. and Bradley, P. A.: Ionospheric propagation, in: Propagation of Radio waves, 2nd edn., edited by: Barclay, L. W., IEE London, 313-334, 2003.

Dobrovolsky, I. R., Zubkov, S. I., and Myachkin, V. I.: Estimation of the size of earthquake preparation zones, Pure Appl. Geophys., 117, 1025-1044, 1979.

Hayakawa, M. and Molchanov, O. A.: Seismo-Electromagnetics: Lithosphere-Atmosphere-Ionosphere Coupling, Terra Scientific Publishing Co., Tokyo, 477 pp., 2002.

Hobara, Y. and Parrot, M.: Ionospheric perturbations linked to a very powerful seismic event, J. Atmos. Sol.-Terr. Phy., 67, 677685,2005

Kim, V. P., Hegai, V. V., and Illich-Svitych, P. V.: On one possible ionospheric precursor of earthquakes, Physics of the Solid Earth, 30, 223-226, 1994.

Liu, J. Y., Chuo, Y. J., Shan, S. J., Tsai, Y. B., Chen, Y. I., Pulinets, S. A., and Yu, S. B.: Pre-earthquake ionospheric anomalies registered by continuous GPS TEC measurements, Ann. Geophys., 22, 1585-1593, 2004 http://www.ann-geophys.net/22/1585/2004/.

Mayaud, P. N.: Derivation, Meaning and use of geomagnetic indices, AGU, Washington, DC, Geophysical Monograph, 22, 154 pp., 1980.

Molchanov, O. A. and Hayakawa, M.: Seismo-electromagnetics and related phenomena: History and latest results, TERRAPUB, Tokyo, 190 pp., 2008.

Molchanov, O., Rozhnoi, A., Solovieva, M., Akentieva, O., Berthelier, J. J., Parrot, M., Lefeuvre, F., Biagi, P. F., Castellana, L., and Hayakawa, M.: Global diagnostics of the ionospheric perturbations related to the seismic activity using the VLF radio signals collected on the DEMETER satellite, Nat. Hazards Earth Syst. Sci., 6, 745-753, doi:10.5194/nhess-6-745-2006, 2006.

Namgaladze, A. A., Klimenko, M. V., Klimenko, V. V., and Zakharenkova, I. E.: Physical mechanism and mathematical modelling of earthquake ionospheric precursors registered in Total Electron Content, Geomagn. Aeronomy, 49, 252-262, 2009.

Park, C. G. and Dejnakarintra, M.: Penetration of thundercloud electric fields into the ionosphere and magnetosphere, 1. Middle and auroral latitudes, J. Geophys. Res., 84, 960-964, 1973.

Parrot, M.: Use of satellites to detect seismo-electromagnetic effects, Main phenomenological features of ionospheric precursors of strong earthquakes, Adv. Space Res., 15(11), 1337-1347, 1995.
Parrot, M., Benoist, D., Berthelier, J. J., Blecki, J., Chapuis, Y., Colin, F., Elie, F., Fergeau, P., Lagoutte, D., Lefeuvre, F., Legendre, C., Leveque, M., Pinçon, J. L., Poirier, B., Seran, H. C., and Zamora, P.: The magnetic field experiment IMSC and its data processing onboard DEMETER: Scientific objectives, description and first results, Planet. Space Sci., 54, 441-455, 2006 a.

Parrot, M., Berthelier, J. J., Lebreton, J. P., Sauvaud, J. A., Santolik, O., and Blecki, J.: Examples of unusual ionospheric observations made by the DEMETER satellite over seismic regions, Phys. Chem. Earth, 31, 486-495, 2006b.

Parrot, M., Sauvaud, J. A., Berthelier, J. J., and Lebreton, J. P.: First in-situ observations of strong ionospheric perturbations generated by a powerful VLF ground-based transmitter, Geophys. Res. Lett., 34, L11111, doi:10.1029/2007GL029368, 2007.

Pulinets, S. A.: Physical mechanism of the vertical electric field generation over active tectonic faults, Adv. Space Res., 44, 767773, 2009.

Pulinets, S. A., Boyarchuk, K. A., Hegai, V. V., Kim, V. P., and Lomonosov, A. M.: Quasielectrostatic Model of AtmosphereThermosphere-Ionosphere Coupling, Adv. Space Res., 26(8), 1209-1218, 2000.

Pulinets, S. A. and Boyarchuk, K. A.: Ionospheric Precursors of Earthquakes, Springer, Berlin, 2004.

Pulinets, S. A., Legen, A. D., Gaivoronskaya, T. V., and Depuev, V. K.: Main phenomenological features of ionospheric precursors of strong earthquakes, J. Atmos. Sol.-Terr. Phy., 65, 1337-1347, 2003.

Riggin, D. and Kelly, M. C.: The possible production of lower hybrid parametric instabilities by VLF ground transmitters and by natural emissions, J. Geophys. Res., 87, 2545-2548, 1982.

Rozhnoi, A., Molchanov, O., Solovieva, M., Gladyshev, V., Akentieva, O., Berthelier, J. J., Parrot, M., Lefeuvre, F., Hayakawa, M., Castellana, L., and Biagi, P. F.: Possible seismo-ionosphere perturbations revealed by VLF signals collected on ground and on a satellite, Nat. Hazards Earth Syst. Sci., 7, 617-624, doi:10.5194/nhess-7-617-2007, 2007.

Rozhnoi, A., Solovieva, M., Molchanov, O., Akentieva, O., Berthelier, J. J., Parrot, M., Biagi, P. F., and Hayakawa, M.: Statistical correlation of spectral broadening in VLF transmitter signal and low-frequency ionospheric turbulence from observation on DEMETER satellite, Nat. Hazards Earth Syst. Sci., 8, 11051111, doi:10.5194/nhess-8-1105-2008, 2008.

Sarkar, S., Gwal, A. K., and Parrot, M.: Ionospheric variations observed by the DEMETER satellite in the mid-latitude region during strong earthquakes. J. Atmos. Sol.-Terr. Phy., 69, 1524 $1540,2007$.

Slominska, E., Blecki, J., Parrot, M., and Slominski, J.: Satellite study of VLF ground-based transmitter signals during seismic activity in Honshu Island, Phys. Chem. Earth, 34, 464-473, 2009. 